\title{
Designing for institutional transformation: Six principles for department-level interventions
}

\author{
Gina M. Quan \\ Department of Physics and Astronomy, San José State University, \\ One Washington Square, San Jose, California 95192-0106, USA \\ Joel C. Corbo, Noah D. Finkelstein, and Alanna Pawlak \\ Center for STEM Learning, University of Colorado Boulder, 393 UCB Boulder, Colorado 80309, USA
}

Karen Falkenberg, Christopher Geanious, and Courtney Ngai

The Institute for Learning and Teaching, Colorado State University, 701 Oval Drive, Fort Collins, Colorado 80521, USA

Clara Smith and Sarah Wise

Academic Technology Design Team, University of Colorado Boulder, Boulder, Colorado 80309, USA

Mary E. Pilgrim and Daniel L. Reinholz

Department of Mathematics and Statistics, San Diego State University, 5500 Campanile Dr, San Diego, California 92182, USA

(Received 28 November 2018; published 13 June 2019)

\begin{abstract}
Cultivating institutional transformation has been of recent interest in education research. This theoretical paper presents six principles for supporting sustained change efforts at the department level. Considering change efforts at the level of "principles" is valuable because principles are grounded in theoretical and empirical knowledge, but are abstract enough to be adapted to many contexts. For each principle we argue for its value, drawing on previous literature in higher education, organizational change, discipline-based education research, and design thinking. We then give illustrative examples of how each principle was embodied within the Departmental Action Team (DAT) project. The DAT project facilitates the implementation of effective changes within university science, technology, engineering, and mathematics departments. We conclude with a discussion of how these principles can be applicable across a variety of institutional transformation efforts.
\end{abstract}

DOI: 10.1103/PhysRevPhysEducRes.15.010141

\section{INTRODUCTION}

Institutional transformation has been a central area of focus in higher education. While there exists a significant body of research on how to improve teaching and learning of science, technology, engineering, and mathematics (STEM), there still has yet to be widespread transformation of STEM teaching efforts [1-4]. Understanding how to propagate and institutionalize educational changes is important to both research and practice. These challenges and opportunities motivate national calls to improve undergraduate education [5-7], as

\footnotetext{
*gina.m.quan@gmail.com
}

Published by the American Physical Society under the terms of the Creative Commons Attribution 4.0 International license. Further distribution of this work must maintain attribution to the author(s) and the published article's title, journal citation, and DOI. well as interest in physics education research (PER) [8-10] to better understand change.

In recent years, PER and other discipline-based education research fields have made increasing strides toward understanding the institutionalization of educational transformation $[4,8,9]$. This work has revealed valuable practical knowledge for how to enact institutional transformations. Research shows that change aimed at the scale of the department (rather than at individual faculty or individual courses) is more likely to be effective [8,11]. Studies of systemic change efforts (e.g., Project Kaleidoscope [12]; the Science Education Initiative [13]) reveal strategies of successful change efforts, for example: providing continued resources to support change [13,14], aligning with institutional interests [15], cultivating effective change leaders [16], and celebrating short-term wins [17]. Within this body of work, some have externalized models for the stages and components of effective change efforts 
[15,18]. As an example, Elrod and Kezar's [15] river model provides a roadmap for how to cultivate leadership, assess readiness, and implement changes at the level of an institution. In summary, prior work has identified many valuable practices that support the successful implementation of change efforts, and outlined necessary steps to enact change. However, we believe that these innovations are also guided by essential, yet often implicit, principles, generalized guidelines that connect those practices to deeper theoretical knowledge and values. Therefore, we argue that it is also necessary to articulate principles for enacting change, in addition to articulating productive practices.

Principles bridge research and practice, connecting the "why" of a design (the theory) to the "how" (the practice) [19]. Principles are empirically grounded in prior evidence-based studies $[20,21]$ and are flexible enough that they can be adapted to multiple settings [20-22]. Externalizing an intervention's principles has been a common practice in STEM education (e.g., Refs. [23-26]) and has been recommended as a way to improve propagation of educational interventions [14]. Because principles provide the logic behind specific design features, they support practitioners in being able to apply aspects of a model to new contexts [19,21], assess their progress, and hold oneself accountable to one's values. Principles add value to research, because they enable conjectures about how design features support certain changes. These conjectures can be tested in new contexts, ultimately leading toward deeper understandings of how change works in different contexts [22,27-30]. Understanding how principles hold up in other contexts complements empirical studies of the consequential features of innovations and assessments of fidelity of implementation [31,32].

Within this paper, we describe six principles for effective institutional transformation. These principles come from our experience leading department-level change on the Departmental Action Team project $[8,33]$. Each of these principles will support effective institutional transformation efforts in higher education. Our purpose is not to argue that these are the only or best set of principles upon which to build departmental change efforts. We simply argue that these have demonstrated value for efforts seeking to promote institutional change, especially at the departmental level. They are as follows:

1. Students are partners in the educational process.

2. Work focuses on achieving collective positive outcomes.

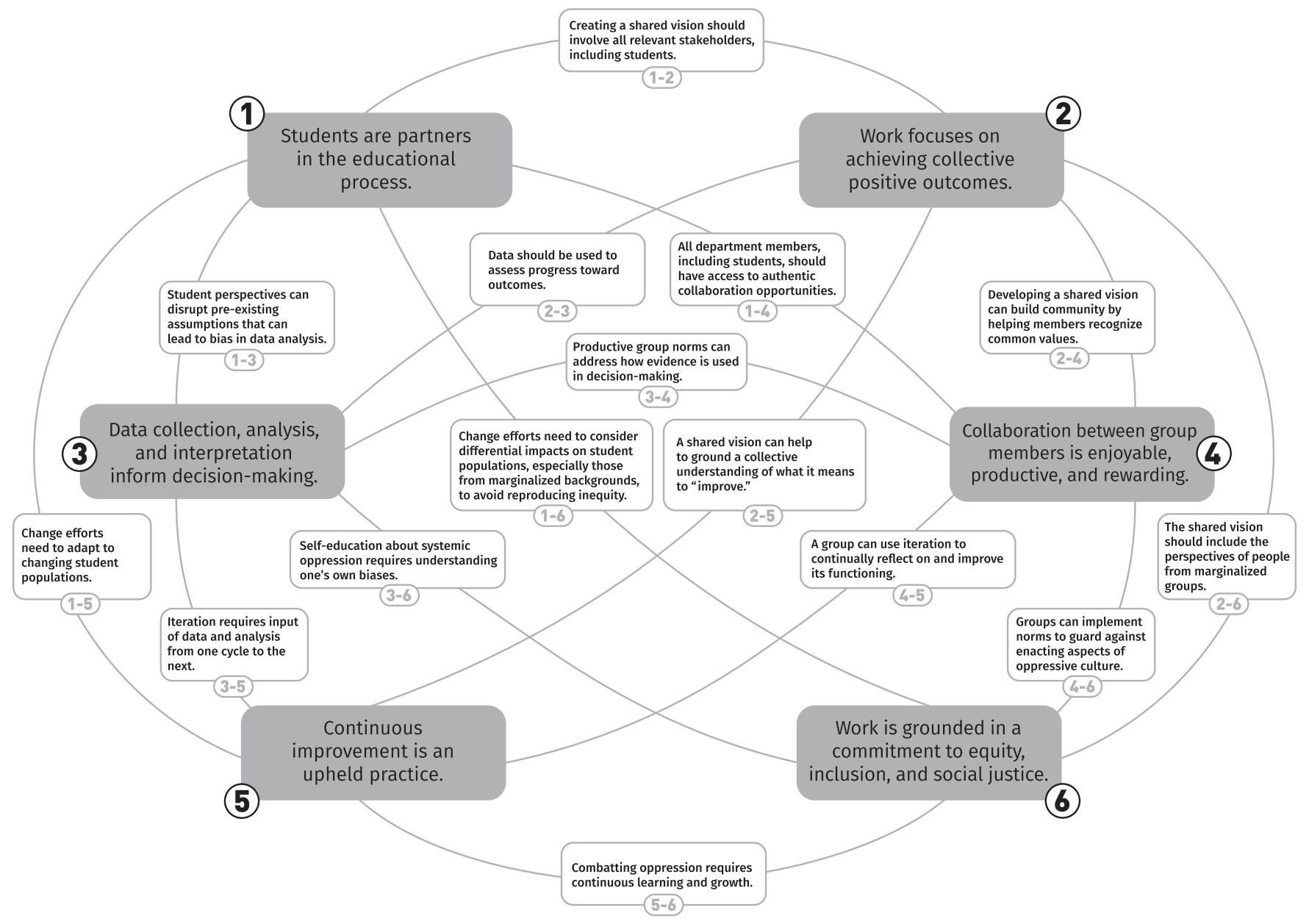

FIG. 1. An illustration of each principle (gray boxes) and the connections between them (white boxes with black outline). 
3. Data collection, analysis, and interpretation inform decision making.

4. Collaboration among group members is enjoyable, productive, and rewarding.

5. Continuous improvement is an upheld practice.

6. Work is grounded in a commitment to equity, inclusion, and social justice.

While the principles are numbered, we think of the principles as equally important, with their numbering serving as a convenient shorthand for referring to them. In addition, these principles are mutually reinforcing; they work together as a coherent set in which each principle connects to the others. We illustrate these connections in Fig. 1, and explore the specific connections between them in this paper.

The purpose of this paper is to demonstrate the utility of six principles for effective institutional change. We see our contribution to the literature as twofold:

- We bring together several disconnected areas of existing research into six principles for effective change. Synthesis of this literature deepens our understanding of the ideas and allows us to identify areas of coherence. For example, we find that the principles themselves are mutually reinforcing (see Fig. 1), which we elaborate on in this paper.

- We emphasize the value of articulating "principles," in addition to effective change strategies and practices. Naming one's principles helps externalize much of the wisdom of many practitioners bring to bear in their change work. This not only is useful for change agents, but also contributes to our field's knowledge of the nature of change in higher education.

For each principle, we describe several "components" and discuss the importance of each component based on various bodies of literature. Then we demonstrate an application of each principle within one change effort, the Departmental Action Teams project.

\section{CONTEXT AND APPROACH}

\section{A. The Departmental Action Teams model}

Our project supports department-level changes through Departmental Action Teams (DATs). DATs are working groups of four to eight individuals (faculty members, students, and/or staff) who meet regularly over a year or more to work on a broad-scale issue related to undergraduate education in their department. While the membership of DATs vary, every DAT we have worked with has had faculty members. Staff members are typically the staff who are connected to the focal issue in some way (e.g., undergraduate advisors). Examples of issues that DATs have worked on include improving course alignment across the curriculum, assessing disciplinary skills, improving inclusion of underrepresented students in the major, and building a sense of community in the department.
DAT participants work toward enacting sustainable changes related to their focal issue by creating new departmental structures or processes and by shifting cultural beliefs, values, and norms.

External facilitators are an essential aspect of the DAT model. Facilitators support the DAT in enacting the DAT core principles to achieve meaningful change. Our facilitator training aims to cultivate the knowledge, skills, and tools that support DATs in enacting the six principles. External facilitators help manage the group logistics, focus on developing a functioning working team, provide customized support to help the DAT achieve its goals, and increase the capacity for change within the DAT's department.

The DAT project's core principles have been central to the development of the DAT model. DATs were first created by several members of our project team in the context of a project creating cultural change within undergraduate STEM departments $[8,33,34]$. By culture, we mean the visible surface features of an organization such as structures and processes, as well as the deeper values, norms, beliefs, and assumptions [35]. The DAT project's objective is not tied to a specific discipline or educational innovation (e.g., supporting departments in implementing studio-style classrooms). Instead, the objective is to foster cultural features that allow departments to enact change successfully. These principles were developed as a way to articulate those cultural features for ourselves and to DAT participants.

Our principles have directly informed the design of the DAT model, including the structuring of activities, the composition of DAT membership, and our assessment of DATs. The principles are independent of any DAT's focus; that is, they do not dictate what a DAT is to achieve, but do specify approaches that will support the DAT in achieving their goals. One of our long-term goals is that DAT members come to value these principles and apply them to other change efforts within their departments.

Throughout the paper, we consider the principles' applicability to departments and groups of departmental members (such as DATs). For this paper, we will describe the principles' enactment within a "group," where the group is a team of people in a department aimed at making some change in that department.

\section{B. Our process for generating principles}

Initial conceptualizations of our principles were grounded in the organizational change literature, the higher education literature, and our personal commitments and values. We also drew from our extensive experience as facilitators over multiple years. As we implemented them into our practice and as our team added members with diverse sets of expertise, we drew from other bodies of relevant literature to refine our definitions of each principle. These bodies of literature included STEM education research, facilitation, 
and design thinking. This paper presents our principles as grounded in the bodies of work that most informed our thinking: organizational change (e.g., Refs. [35-37]), higher education (e.g., Refs. [38,39]), STEM education and discipline-based education research (e.g., Refs. [2,3,9]), facilitation (e.g., Refs. [40-42]), engineering design and design thinking (e.g., Ref. [43]), and faculty learning communities (e.g., Refs. [44-46]). These ideas also resemble ideas from other communities such as communities of practice (e.g., Refs. [47-49]), leadership theory (e.g., Refs. [50-52]), and networked improvement communities (e.g., Refs. [53]), though we do not explore those areas of literature in depth in this paper.

While this paper presents principles as fixed ideas that have become instantiated in practice, the actual process of refining the DAT model's core principles has been ongoing. We have engaged in an iterative process of putting principles into practice, reflecting on practice, drawing on new literature, and refining the principles. This paper presents the most recent version of each principle.

\section{Illustrative vignettes}

We use illustrative vignettes to show what principles can look like in practice. These vignettes also demonstrate the utility that principles bring to change work. As part of our larger research goals, we have been collecting data on each DAT, including interviews and focus groups with DAT members, DAT meeting notes, and facilitators' reflections in journals. Note-taking responsibilities are shared between DAT facilitators. From our experience, meeting notes are significantly detailed and are nearly verbatim records of the conversation. When possible, we triangulated our interpretations of meeting minutes with interview transcripts.

To identify illustrative examples of each principle, we began with making transcripts of all focus groups and oneon-one interviews. We reviewed these transcripts and the meeting notes from each DAT and flagged instances where a principle was salient. We then selected clear, understandable examples of each principle for this paper. During our analysis, we loosely drew from conversation analysis [54] and interaction analysis [55,56] to develop claims about participants' goals and orientations toward the DAT's work, as well as how the principle was mediating their activity.

We do not make claims about the representativeness of these examples across our data set. The purpose of the examples is to help readers envision how a principle could be applied in practice and to serve as a "proof of concept" that the principle could exist within a change effort.

\section{DATs featured in this paper}

This paper features DATs from three departments. Potions and Herbs are both physical science departments while Runes is a life science department (all department names are pseudonyms). The stated goal of the Potions
DAT was to increase inclusion of students who are women and underrepresented minorities (who they defined as Black, Latinx, and Native American) in their department. This DAT included students, staff, a postdoc, and faculty. The Herbs DAT focused on understanding the extent to which Herbs majors were learning disciplinary skills. This DAT was composed of students and faculty. The Runes DAT focused on curricular coordination of courses in the Runes curriculum. This DAT was composed of tenure-track and non-tenure-track faculty.

\section{THE CORE PRINCIPLES}

In this section, we present our core principles. Each subsection begins with a short paragraph description of the principle (italicized), which is our team's consensus definition of the principle for internal and external use. We then provide detail of each of the principles' components (summarized in Table I). Next, we discuss the affordances and challenges of implementing the principle. We conclude each section with a vignette of the principle's enactment in practice.

\section{A. Principle 1: Students are partners in the educational process}

Students are empowered to make meaningful decisions about their own education and to impact broader decision making around undergraduate education. Faculty and staff actively seek out student input on the group's activities and structure on an ongoing basis. Students see themselves as having a say in how the group's decisions are made. There is continuous student involvement to meet the needs of the current student population.

Within the higher education literature, there is an emerging body of work discussing the value of having students work in partnership with faculty on efforts related to educational change [57-61]. This work, "students as partners" (SAP), has most commonly been implemented in the context of classrooms, so we draw heavily from that literature in this section. While we believe that all stakeholders should be invovled in decision making about education, we specifically choose to emphasize students in this principle because they have historically been left out of these conversations.

\section{Components of the principle}

Students have unique expertise. Many STEM education researchers have argued that students have substantive, sophisticated ideas about STEM subject matter (e.g., Refs. [62-64]). In addition, others have argued that students have a deep understanding of what it is like to learn subject matter. This has led to instructors partnering with students to better design classrooms and curricula to 
TABLE I. Summary of each principles' components.

\begin{tabular}{|c|c|}
\hline Principle & Components \\
\hline 1. Students are partners in the educational process. & $\begin{array}{l}\text { Students have unique expertise. } \\
\text { The group seeks diverse student perspectives on an ongoing basis. } \\
\text { Students and faculty share power and decision making. } \\
\text { Students see themselves as partners. }\end{array}$ \\
\hline $\begin{array}{l}\text { 2. Work focuses on achieving collective positive } \\
\text { outcomes. }\end{array}$ & $\begin{array}{l}\text { The group focuses on outcomes. } \\
\text { A shared vision guides change. } \\
\text { Group members co-create the vision. }\end{array}$ \\
\hline $\begin{array}{l}\text { 3. Data collection, analysis, and interpretation } \\
\text { inform decision making. }\end{array}$ & $\begin{array}{l}\text { The group collects multiple, relevant forms of data. } \\
\text { The group is analysis driven instead of data driven. } \\
\text { The group counteracts biases when analyzing data. }\end{array}$ \\
\hline $\begin{array}{l}\text { 4. Collaboration among group members is } \\
\text { enjoyable, productive, and rewarding. }\end{array}$ & $\begin{array}{l}\text { All members have access to authentic collaboration. } \\
\text { Productive collaborative norms are implemented and upheld. } \\
\text { Common activities help build community. }\end{array}$ \\
\hline 5. Continuous improvement is an upheld practice. & $\begin{array}{l}\text { Flexible, ongoing change processes support sustainability. } \\
\text { Iteration leads to better solutions. } \\
\text { Ongoing demonstrated progress generates momentum. }\end{array}$ \\
\hline $\begin{array}{l}\text { 6. Work is grounded in a commitment to equity, } \\
\text { inclusion, and social justice. }\end{array}$ & $\begin{array}{l}\text { The group recognizes the systemic nature of oppression. } \\
\text { Members feel individual responsibility toward fighting oppression. } \\
\text { The group considers impact on marginalized groups. } \\
\text { The group recruits diverse membership. }\end{array}$ \\
\hline
\end{tabular}

meet students' needs [65-67]. Student-faculty partnership has been especially beneficial when instructors have different backgrounds than the students [66]. This work suggests that students have unique knowledge of what it is like to be a student in a particular institution, and should be included in the design of changes that impact students.

This idea is aligned with work in design thinking and participatory design that argues that users understand themselves better than designers and users should contribute to a products' design $[43,68-70]$. Extending this idea to university departments, we argue students should be involved in the design of changes that will impact them (e.g., in the implementation of curricular changes [66]).

The group seeks diverse student perspectives on an ongoing basis. Students are a diverse population, and so it is important to not treat them as a monolithic group. Colleges and universities now educate more students than at any point in the past, and these students are increasingly diverse along many dimensions [38] (e.g., gender and gender identity, race and ethnicity, socioeconomic status, family college attendance, sexual orientation, religion, veteran status, physical and mental disability, citizenship, age, the need to support dependents). Supporting the success of all students requires one to understand the unique experiences of students whose perspectives have historically been excluded (e.g., gender and sexual minorities, students of color, first generation students, veterans, students with disabilities, students with dependents, undocumented students, and students at the intersections of these identities.) [39]. Therefore, change efforts should find ways to meaningfully incorporate a diversity of student perspectives.
Additionally, the rapid evolution and diversification of student populations means that what is true about students at a university today will almost certainly not be true in 5 to 10 years. Therefore, student partnerships must be an ongoing component of a change effort.

Students and faculty share power and decision making. True partnership entails the sharing of power. However, given institutionalized power dynamics, students typically have much less power than faculty members. This is because in most departments, faculty members control departmental policies, curricula, and assessments. Faculty members also hold expertise and legitimacy that affords them power in educational settings [59]. These structural and cultural features make it challenging for students and faculty to share power more equally.

Sharing power means that students have a say in decision making about undergraduate education. This differs from relationships in which faculty merely seek student input or feedback when needed $[58,66]$. The organizational change literature defines participative decision making (PDM) as a system in which a wide variety of members of an organization are involved in making decisions. Research in K-12 settings suggests PDM leads to better decisions, more effective implementations, improved communication across levels, greater feeling of ownership, and improved climate [71] (cf. Ref. [72]). PDM supports the idea that students should have decision-making power in departmental changes that affect them.

We argue that power can never be equally distributed between students and faculty because students and faculty are differently situated within an institution. Nevertheless, 
it is possible for participants in a change effort to recognize and reduce power differentials between these groups. The SAP literature identifies reciprocity as one concept for power sharing [57]. Reciprocity is where students and faculty members are both able to contribute their ideas and perspectives equitably and learn from each other [57]. Through ongoing dialogue and working toward reciprocity, all parties can contribute meaningfully and stand to gain from a student-faculty partnership.

Students see themselves as partners in the change process. Within SAP, it is not only important that students contribute as partners, but that students also recognize themselves as legitimate partners. Complementary to students' self-recognition as partners, it is also important that faculty see students as partners as well. Together, this selfrecognition and recognition by faculty both contribute to students' roles within the partnership $[73,74]$. That is, in order for students to truly be partners, they must see themselves as partners and be seen by others as partners.

Seeing oneself as a partner can support the development of students' attitudes and relationships toward the broader university or disciplinary community. In a literature review on SAP, Mercer-Mapstone et al. found that common outcomes of partnerships included increased engagement, motivation, self-efficacy, sense of belonging, and positive identity shifts [57]. Within STEM disciplines, such affective constructs have been shown to influence long-term persistence in STEM [75-78].

\section{Implications of adopting this principle}

SAP comes with many affordances to groups engaging in departmental change efforts. Students have rich ideas and are best situated to understand how a change initiative will impact student populations. Partnerships can also benefit students through increased motivation, confidence, sense of belonging, and identity within a discipline.

SAP can be challenging to implement, however. Sharing power between students and faculty is an inherently complex and emotional process $[57,60]$ that requires ongoing reflection, maintenance, time investment, and resources [59]. Like any attempt to mitigate power dynamics, it is possible to make mistakes [57]. Even the most well-meaning faculty members can fall into the trap of essentializing or infantilizing students even if they are genuinely trying to work with them as partners. Additionally, SAP goes against long cultural patterns of having faculty as the sole deciders in a department. Disrupting this norm could be met with awkwardness, confusion, and resistance.

We believe that this disruption, however, allows SAP to have the potential to be transformative to institutions. Through disrupting hierarchies, SAP can create space for more expansive visions of working relationships between students and faculty [61].

\section{Enacting the principle: Student members of DATs}

One way that SAP is embodied within the DAT project is through student membership on DATs. DATs are highly encouraged (though not required) to include student members. The DAT project has stipends for student members, which incentivize student participation and normalize student membership on DATs. In some cases, student members have been included in the formation of DATs, whereas other DATs have included student members after the DAT's formation.

As described in the previous subsection, fostering partnership between faculty and students requires extra work. DAT facilitators ensure that student perspectives are legitimized through revoicing and affirming students' ideas, which positions students as having expertise. Facilitators also ensure that work gets distributed in equitable ways (e.g., not pigeonholing students into certain roles, like "notetakers") and that students are included in decision making.

The Potions DAT [79], which focused on increasing the inclusion of students who are women and underrepresented minorities, provides an example of student partnership on a DAT. After spending much of year 1 analyzing student data, the Potions DAT decided to invite students in year 2 to contribute toward ideation and implementation of inclusion projects. One focus group exchange between Cassie (staff member) and Sally (tenure-track faculty member) highlighted how the "student perspective" was valued by DAT members.

Interviewer: And how do you think it's worked having such a mix of people from students and faculty and staff? Cassie: ...It allows for a very diverse set of opinions and perspectives... having actual undergrads in here that are like "hey this is actually how it is" you know.

Sally: Yeah...when we were figuring out how to invite people to [an event series], I wrote a draft email to invite people and one of the undergrads looked at it and said "yeah, this is a huge wall of text, no undergrad is going to read this. Can I rewrite it so that an undergrad might actually notice it?" And I just thought great, yeah, I never would have thought of that...I think that makes it much more connected to people's actual experiences in the department than a bunch of faculty thinking like huh, maybe the students want more pizza or whatever we would imagine the issues are. And I don't think I appreciated how great that was going to be until doing it. It's been really, really wonderful.

Within Cassie's quote above, she valued different perspectives of DAT members (students, faculty, and staff). It was especially important to hear "actually how it is" from the undergraduates. Sally then gave an example of a situation in which the undergraduate student perspective helped her write an email. She characterized this partnership as helping the work be "much more connected to people's actual experiences in the department" compared to conversations 
among faculty only. Students on the Potions DAT similarly reported feeling like their perspective led to positive change in the department. Willow (a graduate student) and Cedric (an undergraduate) responded to a question about whether DAT members felt "empowered" as a result of the DAT.

Interviewer: [One project goal is that DAT members]... feel more empowered to have an impact in the departments...how much do you think that happened?

Willow: As a graduate student it's kind of given me a way to voice what I'm thinking...if I bring something up here, the faculty on this committee have the potential to influence other faculty in the department that I would just never be able to reach and would be terrified to try to talk to anyway.

Cedric: I definitely feel much more empowered being part of this to know that even as an undergrad that my voice is represented in the department. That's huge. It makes me feel like I want to get up, I want to get off the couch, I want to do these activities, plan, organize, execute...it's at least good to have open communication between all these levels. You know, I've been able to effect change already.

Willow described one mechanism by which the DAT created opportunities for her to influence the department: faculty on the DAT heard her concerns and communicated them to other faculty. She said she would have been too "terrified" to talk to those faculty otherwise, suggesting that the DAT transformed her relationships to departmental faculty by creating a new avenue for her ideas to be communicated to faculty. In a different vein, Cedric described his experience on the DAT as giving him a stronger sense of agency and motivation, which is aligned with prior research that demonstrates how SAP supports student engagement [57]. Within Cedric's quote, there is strong positive affect and a sense of pride in the work he has done so far. This work motivated him to take a more active role in enacting change in the future, suggesting that student agency is a strong benefit of inviting students to be partners.

\section{B. Principle 2: Work focuses on achieving collective positive outcomes}

Group members use a shared vision to guide work aimed at achieving change. The process of developing the group's vision includes a diversity of relevant stakeholders. Focusing work around outcomes of the long-term vision, rather than immediate problems, allows the group to be more creative, cooperative, and flexible.

One significant thread of the organizational change literature highlights the importance of shared vision and a focus on outcomes in creating sustainable change [36,41]. We draw on these ideas to inform our second principle.

\section{Components of the principle}

The group focuses on outcomes. It is easier for a group to achieve complex change when it has an "outcomes focus" as opposed to a "problem focus," that is, a focus on what it is trying to create rather than what it is trying to eliminate. An example of a problem focus would be that "students show up unprepared for upper-division courses" whereas an outcomes focus would work toward "a well-integrated course sequence." When a group is in "problem solving mode," individuals will tend to focus on diagnosing and treating problems that are immediately apparent $[36,41]$. This leads the group to treating short-term, surface-level issues instead of understanding deeper root causes. Additionally, with a problem focus, individuals often default to their individual preferred solution, which can result in disagreement.

In contrast, an outcomes focus promotes flexibility and adaptability because any given outcome can be achieved in many ways [15]. An outcomes focus also promotes creativity by opening up space for members to envision new possibilities. To have an outcomes focus, it is necessary for groups to collaboratively agree to a shared vision.

A shared vision guides change. In the context of a change effort, shared vision is a deep, vivid, compelling understanding of what a group is trying to achieve that is co-created and co-owned by the members of the group. A shared vision is inextricably connected to an outcomes focus in that it answers the question, "What do we want to create?" [36].

A shared vision provides a group with a strong pull towards a desired outcome. Focusing on positive, imagined futures (rather than problems) motivates and excites groups [41]. Commitment to achieving a vision also encourages group learning and skill-building because clarity about the vision provides clarity about what skills or knowledge are needed to enact it. Having an overarching vision promotes creativity and innovation by opening up space to envision more flexible solutions [40]. Additionally, when a group has a vision that is truly shared, each member of the group is more committed to the group. The vision binds the group together, encouraging its members to see each other as on the "same team" and therefore to overcome their differences in the service of achieving the vision [41].

On the other hand, a group that does not have a shared vision will have a difficult time achieving complex change. If the members of the group do not have a vision at all, then they may not have much internal motivation, they may not invest much time in their own development, and they may be much less likely to take risks or think outside the box [41]. If members of the group have visions that are misaligned, then the group may stagnate as each member tries to pull the group in a different direction.

A shared vision also directly supports the change work itself. Elements of the shared vision become criteria that 
members use to make decisions, and groups use the shared vision to identify which forms of evidence would indicate progress toward that vision. These ideas relate to the concept of "backwards design," in which curriculum is designed and assessed with respect to the most important outcomes [80]. In starting from a shared vision, groups are able to focus their work on the outcomes that are most important to them.

Group members co-create the vision. In order for a vision to be meaningful to the members of a group, they must participate in its co-creation. Within any community, members have different ideas about what the community is and should be [48]. For example, students, faculty, and staff all have different values, concerns, and aspirations about their department. A vision that is co-created by members of all these groups will incorporate these diversity of stakeholders' perspectives, making it more likely that members are committed to the vision [38]. The participation of diverse stakeholders, including students, in the cocreation of the vision is also aligned with principle 1 .

This approach is different from having a subset of the group develop a shared vision for the whole group and then trying to get others to "buy in" to the vision (i.e., commit to a vision that they had no part in creating). Visions that are handed down from leadership are unlikely to garner true commitment from nonleaders who are expected to buy into the vision. More often, this approach results in compliance, apathy, or resistance [36].

\section{Implications of adopting this principle}

Focusing on achieving collective, positive outcomes comes with many affordances. A focus on a shared vision rather than a focus on fixing problems allows the group to be more creative, cooperative, and flexible. Working toward a shared vision gives the group motivation to take on difficult tasks. The shared vision also forms the backbone of measurement criteria, and thus supports the alignment of vision, work, and assessments.

Developing a shared vision can be challenging, however. Groups often want to focus on "doing the work" (by which they often mean taking action) rather than visioning (and related activities like goal setting or self-assessment) which can feel like inaction. However, disagreement on what "the work" is can often be a source of conflict in groups. It is important to consider that doing the work and visioning are not dichotomous, but rather, that visioning is necessary toward ensuring that the work is meaningful.

\section{Enacting the principle: Ideal student activity}

One way that we designed toward this principle in DATs was through the ideal student activity developed by Savina, Gross, and Danielson [81]. In our implementation of this activity, each DAT member is given a pad of large sticky notes and asked to imagine an "ideal student" graduating from their department. DAT members brainstorm characteristics of an ideal student such as their knowledge, skills, behaviors, and values. After writing their responses, participants stick them on the wall, collectively organize them according to common themes, and discuss the themes and how they inform the work of the group. Consensus themes form the backbone of a vision for the DAT's work.

In guiding these visioning activities, the facilitators work toward helping the conversation move from specific features to deeper goals. Often, groups can get bogged down by focusing on specific details [40]. When this happens, facilitators help the group distill common goals from specific examples.

Consider the implementation of the ideal student activity discussion in Runes. As soon as the discussion began, the participants began an elaborated conversation about whether students had specific content knowledge and skills in the Runes curriculum. Then, a facilitator asked a question to shift the conversation from specific course objectives to more generalized scientific skills (e.g., reading, scientific process).

Facilitator 2: Can I clarify what everyone means by learning goals? Would reading, having skills around data, scientific process, are those learning goals?

Anne: In most classes, the learning goals are very specific scientific pieces. These other skills are more tools that I feel have been ignored. I agree with [Bart] that we need to make sure that the learning goals don't disappear. I feel like there are some basic tools that the university isn't recognizing, that apply to our majors as well as every other major on campus that our students leave without having. Like how to find a scientific paper or read it.

Sophia: They get to courses and they can't read a graph. I differentiate learning goals and course goals, with course goals being bigger picture.

Karen: Which do you test?

Sophia: I test on learning goals, which build towards course goals.

Bart: I see those skills as tools that everyone should have, and they should be tools that are used to accomplish understanding, or the learning goals.

After the facilitator's bid to shift to a higher level of abstraction, DAT members began discussing more generalizable learning goals. The group then began to identify the learning outcomes that "every [student] should have" but that "our students leave without having." Through this conversation, they recognized a need for having higherlevel learning goals across the major.

Shortly after articulating what was meant by learning goals for students, the group created four "buckets" of core ideas based on their sticky notes. These buckets formed the basis of the DAT's shared vision for undergraduate education in their department: 
- Ability to find, read, interpret, evaluate, and communicate information.

- Understanding the scientific method and nature of science (e.g., critical thinking skills, application).

- Integration across the curriculum and sustainability of this integration. Learning goals for the major (knowledge) and practices (skills).

- Initiating independent learning, and research or mentoring opportunities. Hands-on skills and experiences.

In a post-DAT interview ( 20 months later), the visioning activity was still salient to Sophia:

[The visioning activity] was a really good thought experiment and we actually keep going back to that... Through that process we identified some areas of concern for us in that while a lot of our courses have learning goals, we don't really have learning goals across our major. So we started developing some strategies for how to try to address that.

Within Sophia's statement, we see that the visioning activity helped identify "areas of concern," including coherent learning goals across the major. Her statement "we actually kept going back to that" suggests that the shared vision was used to inform work throughout the DAT process.

\section{Principle 3: Data collection, analysis, and interpretation inform decision making}

The group collects multiple forms of evidence about undergraduate education (e.g., institutional data, research literature) on an ongoing basis. Group members actively identify and avoid bias in interpreting data by distinguishing observation from inference, developing multiple interpretations of the same data set, considering both systemic and individual factors, and working toward individuals' cultural proficiency and understanding of others' perspectives. These interpretations, rather than personal preferences or idiosyncratic anecdotes, are what drive decision making.

The idea that organizations should be "data driven" in their decision making has been on the rise over the last several decades [29]. While we agree with the basic premise of this idea, our third principle adds nuance by emphasizing that thoughtful analysis and mitigation of bias are critical to data use. This shifts the focus of this principle from being data driven to "analysis driven" [29,82].

\section{Components of this principle}

The group collects multiple, relevant forms of data. Data relevant to departmental change come in many forms, such as assessments, interview and focus group data, survey data, institution-level data, and background literature.
These come from different sources including Institutional Research offices, internal departmental assessments, and classroom assessments. Using multiple forms of data reveals different facets of complex issues and draws attention to systemic factors that are difficult to see with more narrow data [83]. Being systematic in the collection and use of multiple forms of data over time can support better decision making through making it possible to meaningfully evaluate progress over time [7].

It is necessary to consider the relevance of a given form of data. Often in educational settings, it can be easy to collect data that are easy to measure, but are not necessarily tied to the outcomes valued by the group. Having a clear shared vision about what the group values, in alignment with principle 2, can help the group collect more meaningful, relevant data [84].

The group is analysis driven instead of data driven. The collection of data alone is not enough for decision making [84]. Groups also need to develop interpretations through analyzing the data carefully [40,85]. Kezar [38] explicitly describes how data are separate from knowledge. She defines knowledge as the interpretation of data and points out how a single data set can lead to multiple conclusions and interpretations. Thus, the careful choice of appropriate analysis techniques is as important as the choice of data sources that feed into the analysis. We refer to this as being analysis driven instead of data driven $[29,82]$.

Thoughtful analytic techniques involve developing interpretations that are appropriate for the given form of data. Any form of data has limitations in what kinds of claims can be developed from it.

The group counteracts biases while analyzing data. To analyze data well, it is important to actively identify and avoid bias in interpreting data. Being aware of common biases can help group members notice when they are enacting them. An example of a common bias is confirmation bias, in which individuals interpret data in ways that fit their existing ideas [86]. Another is the availability heuristic, which states that individuals tend to rely on the most accessible examples when making decisions, even if these examples are not representative [87]. Developing a multiplicity of explanations of the same data set, in particular ones that consider both systemic and individual explanations, can help avoid some forms of bias. Incorporating a diversity of perspectives (such as student perspectives, in alignment with principle 1) can support the creation of a breadth of explanations.

Groups can also engage in processes that counteract bias. For example, groups in which members articulate assumptions and predictions ahead of time can notice inconsistencies between predictions and observations, which can reveal biases [42] and create cognitive dissonance that is helpful for learning [38]. Another practice is for groups to 
separate observation (articulating what they see in the data) from inference (generating explanations of the data) because those can often become conflated in conversations about data [42].

\section{Implications of this principle}

Effectively using data to centrally inform a change initiative can lead to productive insights for groups. Multiple forms of data help groups understand different facets of complex phenomena. Groups that are intentional about their choice of appropriate analytical techniques can more effectively generate meaningful knowledge from their data. Finally, explicit attention to bias can help group members counteract biased interpretation of data.

However, there are many challenges to engaging with data in ways that align with this principle. As suggested above, the quality of the data that a group uses matters. Some groups gather meaningless or insufficient data, perhaps because they are unfamiliar with the variety of types and sources of data available to them [85]. On the other hand, often it can be easy for groups to gather an abundance of data, but not know how to use it meaningfully [40]. In either case, groups can default to overly biased or anecdotal interpretations in their decision making, especially if they do not have a habit of explicitly attending to bias in their work.

\section{Enacting the principle: Encouraging use of evidence}

DAT facilitators support this principle by encouraging DATs to use evidence. When DAT members are overrelying on personal anecdote or bias, facilitators use probing questions to help DAT members justify their reasoning, consider what forms of evidence would support their understanding, and disrupt potential misuse of data. Explicitly questioning "how do you know what you know?" and "what forms of evidence would support your reasoning?" supports DAT members in developing these metacognitive inquiry skills for themselves.

DAT facilitators utilize their background in education research to support DATs in using data. Facilitators have knowledge of what forms of data are possible to gather and help participants in accessing these data. This can involve connecting DATs to institutional research offices, helping DATs learn of validated instruments related to the DAT's focal issue, and bringing in relevant background literature.

Now we turn to an example of a facilitated discussion in the Runes DAT that led them to look at data. Runes faculty were discussing how to restructure prerequisites for courses in their major. A facilitator noticed that they were making suggestions without fully understanding the order in which students were actually taking courses:

1. Anne: The teaching committee will probably resist adding new prerequisites, because [our computer system] doesn't handle them well.
2. Sophia: We could just make something a pre-req for [course B1] or [course B2].

...

6. Elly: If we had to pick a course to make [course M] a pre-req for, I would recommend [course B-lab]

7. Sophia: If they could take [B-lab] earlier...it depends on where we want $[M]$ to get used.

...

16. Facilitator 2: The first step is mapping out what is actually true...would it help to know what students are actually doing? It's possible to get some data.

17. Karen: We could ask [associate chair] and the advising staff.

18. Facilitator 2: Right now it seems to be anecdotal. Is there a clear sense of what is going on?

...

44. Bart: it would help to get data on [B] and [B-lab], which seem to be quite problematic. We could easily find out when students are taking it, for sure, and have the numbers to support that. I'll poll the class, and then 72 percent are seniors. It's crazy.

45. Sophia: Can we get that from [our computer system]?

46. Facilitator 2: The institution collects data too.

47. Bart: it would help to do [M, A, B1, B2, B-lab]...

We use this example to illustrate how facilitators prompt DAT members to consider evidence. In the beginning of the conversation (lines 1-8), DAT members discussed possible ideas for assigning prerequisite courses to change the order that students progress through the major. They made these suggestions without fully understanding the problem. The facilitator explicitly pointed out that they were relying on anecdote and encouraged them to consider how they might develop a more complete understanding (line 18). This intervention from the facilitator eventually led Bart to agree that having "numbers to support that" would be helpful (line 44). They then discussed what kinds of information they would want to have, and where they might find it. Following this conversation, the DAT facilitators requested and helped analyze data from the Institutional Research office.

In a postinterview, Bart was asked to reflect on what role the facilitators played in the DAT. He brought up how the facilitators encouraged the DAT to look at data:

I think a great example of [the importance of the facilitators] was I talked about the data that we needed to gather for the undergraduate courses, and did it really support our thought, you know, on this process. When are students taking these classes? Are they taking it in their sophomore year or their senior year or their junior year, and when should they be taking these classes? [The facilitators] got that together really quickly and really fast for us. 
The above quote highlights how data were helpful toward helping the DAT understand the order that students were taking courses and recognizes the facilitators' roles in accessing that data. His statement, "did [the course data] really support our thought... on this process?" suggests that Bart recognized that DAT members'perceptions can sometimes be flawed and looking at data can give them a more accurate understanding.

\section{Principle 4: Collaboration among group members is enjoyable, productive, and rewarding}

\begin{abstract}
All members of the group are collaborators with equal access to contributing to decision making. The group develops community through activities such as eating together and having celebrations. Members of the group interact with one another in functional and productive ways.
\end{abstract}

This principle focuses on the interpersonal and affective components of group functioning. While it may be tempting, especially in academic culture, to ignore these issues as irrelevant to "getting work done," attending to the social and emotional needs of group members supports them in being productive and creating change.

\section{Components of this principle}

All members have access to authentic collaboration. Complex change cannot be carried out by isolated individuals [38]. A department that is interested in creating change must provide avenues for meaningful collaboration to make the change possible. Moreover, all members of the department should be able to contribute to this collaborative work. This means that every member is heard, has their perspective valued, and has power to make decisions [40].

The idea that all members of a department, regardless of "rank," should be included in collaboration and decision making extends ideas from principle 1 about the need for students to share in power and decision making in order to be partners. Many of the benefits that we discussed related to that principle, such as improved decisions, implementation, communication, and climate, carry over to this principle as well, for groups beyond students.

Productive collaborative norms are implemented and upheld. A good collaboration allows all members of a group to participate and contribute on equal footing. For this to happen, the group must have productive ways of interacting. Norms are the (often implicit) patterns of behaviors within a group or context [40,88,89]. Productive group norms support constructive disagreement, consideration of multiple viewpoints, and equitable ways of doing work [40]. Groups can establish norms around decision-making processes, such as how to use evidence to make decisions in alignment with principle 3 .
Establishing and maintaining effective norms early on helps groups accomplish their work.

For norms to be effective, group members need to have a sense of ownership over the norms and hold themselves and others accountable to them [90]. Thus, it is typically more effective for norms to be developed or agreed to by a group, rather than being imposed from the outside [40]. Finally, it is important for groups to proactively reflect on the value of their norms. Without reflection, groups can inadvertently implement counterproductive norms that they inherited from other social systems without realizing it [91].

Common activities help build community. Good collaboration also involves feeling like part of a community. A community is, in part, defined by its shared values, coordination among its members to achieve collective outcomes, and common activities that bind a group together [47]. Thus, the process of creating a vision and defining outcomes described in principle 2 can support a group in better recognizing what makes them a community. Within departments, a professional community is characterized by a set of shared values (e.g., about education), a sense of collective efficacy (i.e., the belief that department members can accomplish goals), and a sense of interdependence and shared responsibility with one another [40].

One mechanism for building a sense of community is to develop common activities that bring people together, even when those activities do not directly feed into the groups' goals. Patterns of regular activities (e.g., having snacks at meetings [92]) can help define a community as separate from other spaces that do not engage in those activities. Participation in such activities fosters a sense of identity and belonging within the community, which in turn encourages group members to care about the needs and goals of the group.

It is also important to develop communities in which participation feels fun and enjoyable. For example, playful community building activities (e.g., ice breakers) can help members get to know one another on a more personal level. This interpersonal relationship building is necessary for developing mutual trust. Sufficient trust is necessary in collaborative environments so that members are able to share ideas and critiques openly [40].

\section{Implications of this principle}

Adopting this principle can help group members make progress in their work. Ensuring that all perspectives are heard and valued allows the group to make more thoughtful decisions. Explicit attention to building a sense of community fosters trust and investment in the group. Additionally, productive conversational norms enable the group to better listen to one another, generate ideas, and resolve disagreement.

Generating this kind of collaborative culture can often feel unfamiliar to groups, which can lead group members to resist or express discomfort with attempts to do so. 
Members of a department are embedded within larger cultures (e.g., departmental, disciplinary, academic), which come with their own implicit norms of interacting (e.g., we should focus on "real work" without the "distraction" of personal discussions). It is important to consider how those broader cultural features shape group members' expectations for collaboration, because they can sometimes be in tension with the kind of culture advocated for here. Additionally, talking explicitly about "process" is both unfamiliar and uncomfortable for many people, so being explicit about norms does not come naturally to many groups.

\section{Enacting the principle: Celebrating successes}

Facilitators encourage DATs to track and celebrate their progress. As milestones come up, facilitators take time to recognize them and give members the chance to reflect on their successes and feel proud of their work [93]. This helps groups build a shared sense of accomplishment, that gives them momentum to continue their work.

To illustrate these celebrations, we turn to an example from the Potions DAT. One aim of the Potions DAT was to become a standing committee within the Potions department. One DAT meeting took place soon after the department had voted to make the DAT a standing committee. During this meeting, they took time to celebrate their success. Sally (faculty member) and Cassie (staff) reflected on this during a focus group:

Sally: In our last meeting where we just a couple of days ago had the vote about becoming a standing committee, which we'd all sort of been explicitly working towards for a year, we did spend maybe twenty minutes just talking about that and how cool it was and joking about okay maybe now we'll get drunk with power and start a department carnival where we bring in ferris wheels and a roller coaster and take over. (laughs) You know, just kind of like joking around, just sort of celebratory.

Cassie: Kind of like enjoying- Yeah-

Sally: Yeah, enjoying this achievement right?

Within this segment, Sally described an extended moment during the DAT where DAT members celebrated their accomplishment of becoming a standing committee. She characterized this time as "enjoying this achievement." This moment was also marked by joking about the new power that they had. This humor suggests that the environment within the DAT was an informal space where members felt comfortable making jokes. They both elaborated:

Cassie: Yeah both of [the facilitators] are just really good at reading the room and reading the people and understanding that man, that was fun, that was a really awesome twenty minute- Like I think it made everybody happy, like you're pumped up about this thing that just happened. They're really good at just doing that, they're just continually gauging the social and the productive context and just merging them in a good way.

Sally: Right. And I think our little mini celebration part of the meeting stuck out in my mind because I think academics tend to be not that great at that, we tend to be very much like okay, that paper's done, go on to the next thing, like always focusing on what's not finished. Just having a little, like, hey we've been working on this thing for two years and this is a really big achievement, let's just talk about how great it is.

Cassie: I agree.

Sally: It's a little bit embarrassing that it's so unusual but it really is.

Cassie attributed the joking and celebrations, in part, toward the facilitators' ability to "read the room" and "people." She characterized this as merging "the social and productive context." We interpret this statement to mean that facilitators were attentive to building a community that bridged work and socializing. Sally then said the celebration stuck out to her as unusual, since the norm was to "focus on what's not finished." This suggests that the DAT's engagement in celebrations and recognition was not common in other department contexts. We argue that these kinds of practices can be beneficial toward developing a strong community where members feel good about their work.

\section{E. Principle 5: Continuous improvement is an upheld practice}

Group members view change as an ongoing process rather than an event (e.g., they recognize that complex problems do not simply stay solved on their own). Members regularly reflect on how the department can be improved and explicitly attend to long-term sustainability when making changes to the department. Incremental accomplishments are incorporated into the change process to support internal momentum and communicate success to maintain external support.

This principle focuses on the way that department members conceptualize the change process (ongoing versus one-time event) and therefore how they view the sustainability, momentum, and success of change efforts.

\section{Components of this principle}

Flexible, ongoing change processes support sustainability. Continuous improvement foregrounds viewing change as an ongoing process rather than a onetime event [94]. Educational problems rarely "stay solved" on their own, as departments are complex systems with many moving parts [7,53]. Moreover, departments often have structures and values that maintain the status quo [35]. 
For example, a cultural norm of "not stepping on others' toes" can lead department members to avoid changes that impact other faculty. Viewing change as a continuous process that requires ongoing maintenance (i.e., constant growth rather than "solving a problem" and moving on) can help to prevent backsliding and support a change's longterm sustainability [36].

Change processes also need to be flexible enough to adapt as the context changes (e.g., as student populations change, as assumed by principle 1). What works within one department at a given point in time is not necessarily what will work in that same department at a different point in time. Because departmental contexts can shift over time (even as a result of the change process itself), inflexible changes can become problems themselves later on [36]. Garmston and Wellman [40] use the term "adaptive" to refer to flexible change efforts that work toward a particular vision, but whose form may change over time.

In order to support a mindset of continuous improvement, departments have to have structures that allow department members to have a collective understanding of what "improvement" means. In alignment with principle 2, a shared vision can help to anchor this collective understanding of improvement within a department.

Iteration leads to better solutions. Iterative approaches to design involve engaging in multiple cycles of prototyping, testing, analyzing, and refining a product or process, with the goal of making incremental improvements to the design over time based on the new knowledge learned in each cycle. Thus, the collection and analysis of data, in alignment with principle 3 , is central to the iterative design process.

Iterative design typically leads to more sophisticated and creative solutions $[43,95,96]$. This is true in part because each iteration is an opportunity to learn more about the system by watching how the system responds. Iteration also creates opportunities to step back and reflect on how well the current solution serves one's goals by assessing current outcomes with respect to relevant metrics. Additionally, iterative approaches can help groups more productively deal with mistakes, because they can view mistakes as a natural part of the learning process [97]. Finally, literature in design thinking highlights how the process of early iterations can also support the refinement of one's conceptualization of what the criteria are for the design [95]. So, the process of continuous improvement through iteration can support groups in generating better solutions, dealing with mistakes, clarifying their design criteria, and assessing intermediate outcomes on the way to achieving their longterm outcomes.

Iterative design can be valuable for helping a group to continuously improve their own functioning. By continually reflecting on and analyzing their efficacy as a group, they can iteratively refine their group's norms to support themselves in being more functional, in alignment with principle 4 .
Ongoing demonstrated progress generates momentum. Continuous improvement also allows groups to demonstrate ongoing progress, because groups that do work incrementally can continually meet short-term goals. This ongoing demonstration of progress generates valuable momentum that supports the group internally and externally. An internal sense of progress helps the group feel proud of their work. This sense of accomplishment and pride motivates the group to continue to work together [93]. Visible ongoing progress is also politically beneficial as it demonstrates success to external stakeholders [98]—-for example, a group could provide improved retention numbers to a dean to secure additional funding. Thus, a savvy group will tend to build short-term, achievable goals into its change effort to create intentional "early wins" en route to a larger goal, thus demonstrating success along the way.

\section{Implications of this principle}

Emphasis on continuous improvement supports groups in developing more sustainable and effective changes. Viewing change as an ongoing process allows for productive reflection and adaptation, as well as generating internal momentum for the group's work. This principle is particularly valuable because it explicitly addresses how to maintain the support of outside stakeholders (through sharing incremental success with them) and how to work toward sustainability.

One challenge in implementing this principle is the danger of wanting to "get things right the first time." Such perfectionism can often stagnate groups, who get stuck trying to pick the "best" solution, often in times when a best solution cannot be known. Additionally, viewing change as a single event also limits a group's ability to be reflective and learn from mistakes because there is no opportunity to try a second time.

\section{Enacting the principle: Generating forward momentum}

DAT facilitators help DAT members distill short-term, achievable goals from their long-term visions. Early implementation and assessment of those goals help participants develop deeper understanding of their focal issue and identify roadblocks. To keep momentum for the change process, facilitators also build in and highlight "early wins" [98], to generate internal and external support.

The first year of the Potions DAT focused on collecting and analyzing data. In its second year, facilitators asked DAT members to set goals: "If we look back a year [from now], what will we want to have accomplished?" DAT members recognized that in addition to any activities they initiated to address what they had discovered in their first year, they also needed to make sure that there was a mechanism for that work to continue in the future with the support of the department. Thus, they identified one of their overarching goals as "sustaining the DAT," with a subgoal 
of building positive visibility for the group. Related to this goal, the DAT then discussed how to show their progress moving forward. In the meeting minutes a member noted that "Quick and easy wins are very helpful! We can increase the visibility of the DAT." The DAT then spent a year of work focused on generating concrete outcomes.

Focus group data at the end of year 2 from Cassie (staff) and Sally (faculty member) suggest that this focus on measurable progress was productive. As Cassie said,

We're sharing ideas and moving forward with stuff, you know. There's not the like, okay, let's talk about this and then let's talk about it again at the next meeting, and then let's vote on it at the third meeting, and then let's have a second vote the fourth meeting. You know, we're like, let's talk about stuff and it's very action oriented.

Cassie characterized the current work of the DAT as "moving forward," which contrasts having several meetings of just talking and voting before taking action. Cassie also described this as "action oriented," which she viewed positively. Similarly, Sally said,

We've really done multiple big projects, especially this year....Like it's kind of shocking honestly, you know? And I'm very proud of it. I wouldn't have expected at all that we would do even just one piece of that, so it's really totally changed... I guess I think for me it's more just the accumulation of these successes, and seeing they sort of build off each other and the more that we do the more we see we can do. I think there was also a-we did have some discussion about thinking about what's the low hanging fruit, or what are things that we can do that are not going to be controversial that everyone's going to agree are improving the department to kind of start on and build from, and I think that also has helped.

Sally explicitly mentioned the accumulation of successes throughout the year. According to Sally, their work started with identifying "low-hanging fruit," which they used to "build from" in creating future successes. Sally described this process as being unexpected and a source of personal pride. We argue that these positive feelings generated momentum for her as a DAT member. She also saw them as providing momentum for the DAT as a whole, because "the more that we do the more we see we can do." Additionally, we see that Sally characterized the DAT as thinking about external audiences when considering what work to do. This is evidence of the DAT's intent to use its low hanging fruit to build support within the department through demonstrating success.

\section{F. Principle 6: Work is grounded in a commitment to equity, inclusion, and social justice}

Group members recognize the existence of systemic oppressive power structures, so they actively mitigate power imbalances and work to create anti-oppressive structures. Group members consider the impact of their decisions on marginalized groups. Group members feel a sense of individual responsibility toward improving inclusion in the department. The group intentionally recruits a diverse membership.

Our final principle emerges from our team's commitment to equity, inclusion, and social justice. Even for groups that are not working on "diversity issues," alignment with this principle is critical to ensure that the enacted change equitably impacts different populations.

Terms such as equity, inclusion, social justice, and diversity can have multiple, overlapping meanings, so it is important to clarify them for this paper $[99,100]$. Diversity emphasizes representation of different identities within a group, paying particular attention to cultivating membership of those who have been marginalized [101]. The term diverse is used to describe a group with a wide set of member identities (including those from marginalized groups). Inclusion recognizes how a group's practices and mindsets exclude members from fully participating, both at a structural level (e.g., policies) and in more subtle ways (e.g., silencing and undervaluing). A focus on inclusion emphasizes the work of identifying and undoing exclusionary practices so that all members' perspectives are valued and legitimized (cf., Ref. [102]). Equity focuses on fairness in how opportunities to participate are distributed $[99,103]$. We view equity as different from inclusion in that it is focused on how exclusion within a group is connected to larger systems of systemic oppression and privilege $[104,105]$. By systemic oppression, we refer to forces of racism, sexism, homophobia, xenophobia, ableism, and other forms of marginalization that exist within society. An equity focus draws attention to how historical systems privilege certain members of society (e.g., those who are white, male, able-bodied, straight) [106]. A commitment to equity involves purposefully undoing those imbalances through providing resources and opportunities for individuals who have experienced marginalization. Finally, social justice foregrounds historical and present forms of systemic oppression and the goal of undoing the structures that allowed that oppression to exist. While many inclusion and equity efforts can inadvertently include diverse voices into systems that do harm, efforts that attend to social justice work to question and transform the existence of the system itself [107]. Rather than enculturating historically marginalized voices into the current system, social justice efforts transform the system to value new ways of knowing and existing [100,108].

\section{Components of this principle}

The group recognizes the systemic nature of oppression. This principle involves recognizing and mitigating systemic, oppressive power imbalances. University 
departments are not only affected by these broader forms of oppression, they are also sites in which oppression occurs $[101,109,110]$. Prior research has documented how this oppression emerges in interpersonal interactions and subconsciously becomes embedded within departmental cultures (e.g., Refs. [111-114]).

The recognition of systemic oppressive power structures is a necessary step toward the mitigation of oppression. Because oppression is systemic, it is inextricably linked to a group's work and must be proactively addressed if group members do not want to reproduce harmful patterns themselves [115]. Developing group norms around discussing oppression and critically reflecting on one's practices can be one mechanism for promoting inclusion [116,117]. This is an extension of principle 4 in that these norms can act to guard against unwanted behavior rather than simply promote desired behaviors. A shared sense of community, empathy, and trust can also support a group in having these difficult conversations [26,118].

Group members feel individual responsibility toward fighting oppression. In addition to understanding the systemic nature of oppression, group members also recognize that they as individuals often unintentionally reproduce problematic behaviors. Therefore, group members should all feel individually responsible for continually learning and combatting oppression (rather than merely avoiding oppressive behaviors). While our other principles'components focus on the collective, here we explicitly emphasize individual responsibility for combating oppression over collective responsibility. We made this choice because working in collectives can be used by individuals to avoid some of their own individual responsibility toward doing this work.

Members who have this sense of personal responsibility work toward furthering their own learning about oppression. There are several dimensions of learning that are relevant here. One can reflect on one's own implicit biases through tools such as implicit association tests [119] and observational tools [120]. Learning about and valuing the experiences of others who do not share one's background can foster cultural competency and empathy toward others $[121,122]$. Finally, learning about documented best practices relevant to one's role in the department (e.g., inclusive hiring practices [123]) can also help to combat oppressive systems. All of these ideas are aligned with principle 3 in that they involve broadening one's personal sources of data and tools for meaning making, with the goal of becoming more anti-oppressive.

Additionally, learning about oppression is not a linear process in which a person starts as a novice and becomes an expert [122]. Instead, the continuous improvement and iterative design ideas of principle 5 are more appropriate to this type of learning. There is always more to learn about how to combat oppression, and making mistakes in one's actions is inevitable. One must be willing to learn from these mistakes and recognize that improvement is the goal.

The group considers impact on marginalized groups. We define this principle to include considering how any given change effort will impact members of marginalized groups and mitigating harm done to marginalized groups. From principle 1, we know that student populations are diverse, and therefore any department-level change will impact students differently. Changes that primarily support more privileged students contribute to educational inequities [39]. Thus, it is necessary to consider how different populations of students, especially those from marginalized backgrounds, will be affected by a change. These considerations can help to address persistent systemic issues of inequity in STEM education.

The group recruits diverse membership. Finally, it is important to have diverse membership at all stages of a group's work, both with respect to demographic characteristics (e.g., gender identity, race, ethnicity, sexuality, ability) and position within the department (i.e., including faculty of different ranks, undergraduate and graduate students, and staff members). In particular, having diverse perspectives in the visioning process, as described in principle 2 , makes it more likely that the group's work will equitably impact all populations within a department and that all populations will share the vision. Additionally, groups with diverse membership often develop more effective, creative solutions [124]. Having a diversity of perspectives allows the group to understand how changes may impact various stakeholders differently. It is especially important to value the voices of those with marginalized identities, because of their unique lived experiences (cf. Ref. [125]).

While recruiting diverse membership, it is necessary to avoid "tokenizing" members of marginalized groups. Marginalization impacts individuals in unique ways, so the perspective of a person from a marginalized group should not be taken as representative of all people of that marginalized group. Moreover, it is also necessary to consider how those who hold multiple, intersecting marginalized identities have unique experiences [126].

\section{Implications of this principle}

This principle is of critical importance because achieving it is a matter of social justice. Taking this perspective helps groups recognize the ways in which oppression is systemic and inevitably makes its way into the work of university departments. Additionally, it highlights the fact that "diversity" is not just a side issue that may or may not be relevant to any given change effort, but that issues of oppression are woven into everything we do.

This is perhaps the most difficult of our principles to achieve in practice. In general, dominant culture denies the existence of systemic oppression and withholds tools for 
engaging with it productively $[127,128]$. It can be challenging, emotionally charged work for people with privilege to recognize oppression, its systemic nature, and the role they play in maintaining it. This can lead to anger, defensiveness, or fear when they try to do so without the proper support [129]. It is easy to falsely believe that one's work is more anti-oppressive than it really is than to challenge oneself to achieve higher standards. It is also possible to overgeneralize from this principle by believing that harmful views need to be tolerated in the name of "inclusivity." All of this means that aligning with this principle requires ongoing reflection and learning.

\section{Enacting the principle: Considering impact on marginalized groups}

To support this principle, we encourage DAT members to consider how change efforts impact members of marginalized groups within a department. For example, using probing questions such as, "How do we know that this would benefit all students?" and "How does this impact students who have been historically underserved by our department?" can support DAT members in noticing and addressing inequities.

Now we turn to an illustrative example from the Herbs DAT, which was trying to improve the accessibility of an assessment. Because the instrument required written responses, the DAT discussed equity in two major ways: making the writing understandable to English language learners and making the images accessible to students with color blindness. Here, we focus on accessibility to English language learners. In a DAT meeting, Ellen (graduate student), pointed out the following:

I've seen concept drawings and diagrams... If they draw something like this, it's higher in skill. For example, the water cycle... And [a drawing-based assessment] doesn't conflate [correctness] with English language ability. We need to give them a way to communicate that's fair.

Within this quote, Ellen suggested one form of assessment: having students draw diagrams. She pointed out that this type of assessment does not conflate students' knowledge with mastery of the English language, recognizing that some written assessments often use inaccessible language which is challenging for students who are not native English speakers. Her phrasing "we need to give them a way to communicate that's fair" suggested that an assessment that tests skills without relying too heavily on English comprehension would be more equitable than one that does. The group then agreed that accessible language was a priority for the assessment.

At the next meeting, the Herbs DAT looked at questions that DAT members had drafted in subgroups. One question read:
"Two series of data represent two types of tree in a landscape (deciduous vs coniferous)."

Jamie (an undergraduate student) and Laura (faculty member) recalled back to the previous discussion on English language ability:

Jamie: Back to the jargon, I noticed there's a lot of technical terms. We had a long discussion about English learning students who don't have the full vocabulary so we discussed a key, or basic words, to make clear what we mean by it.

Ellen: We talked about coniferous versus deciduous and were like we could say pine and maple but also just draw a symbol.

Laura: They're not supposed to know what is typical of pine tree, they're supposed to look at the graph, so it could be a Fred tree and a Sylvia tree.

Jamie pointed out that the words "deciduous" and "coniferous" may be unfamiliar to English learning students and others who do not know the vocabulary. They recalled several previous ideas to mitigate this including using a key, adding definitions, and using more basic words. Then Laura pointed out that the type of tree was not necessary to answer the question, and implied that they could even use made up names. Ellen was tasked with making a final version of the graph, and she changed the wording of the problem to "species A and species B."

This example illustrates how DAT members considered equity and inclusion within their work. Ellen had initially brought up one equity concern, that the test needed to separate skills assessment from English ability. The group then agreed to that as a criteria for their work and later used that criteria to revise one problem. We see this consideration and attention to students from a marginalized background as an important aspect of doing change work equitably.

\section{DISCUSSION}

Within this paper, we have presented six principles for supporting effective departmental change and used prior literature to argue for the value of their components. Using vignettes, we have demonstrated the utility of the principles when enacted in practice. Each of these vignettes illustrates a productive interaction or component of a DAT. By synthesizing several areas of existing disconnected research, we have deepened our knowledge about change and identified areas of coherence. We have also argued for the value of articulating and externalizing one's principles. We see the articulation of one's principles as not only valuable for change efforts in PER, but for any designbased effort.

Principles do not just live in the big-picture aspects of a group's identity, but they are also enacted in small moments 
in DATs, as illustrated by our vignettes. We argue that each principle is not only present in the vignette, but it is essential to the quality of change work. For example, consider the DAT that specifically attended to equity in developing an assessment that is inclusive. Through considering how English language learning students would interact with the assessment, they were able to develop a tool that more accurately assessed skills. As another example, the DAT that celebrated their work found that principle to be necessary for building a cohesive, motivated community. Principles were not only possible to enact, but supported the success of those DATs.

\section{A. Our principles are a coherent set}

We emphasize that the principles are not an arbitrary set of qualities, but rather they are a connected set of interrelated ideas. In Fig. 1, we illustrated pairwise connections between the principles. We also claim that these principles are mutually supportive beyond these pairwise connections. As an example of connections between principles 2, 3, and 5 is that having an outcomes focus supports a group in knowing the target of their continuous improvement, and careful analysis of data supports the group in knowing whether they are succeeding in making improvements toward those outcomes. To connect principles 1,4 , and 6 , attention to equity and inclusion means that all stakeholders, including students, can authentically participate in the group, and without effective norms for collaborating, the group can embody harmful power dynamics that prevent everyone from being able to contribute. One can also imagine how to draw connections between different combinations. The interconnectedness of the principles means that they are each enhanced by the existence of the others; if any one is not present, the enactment of others will be impacted.

\section{B. Applicability beyond the DAT model}

While we have illustrated principles within the DAT model, we see them as applicable to a wide array of other change efforts. These principles are flexible enough that they can support a variety of goals and allow for emergence of outcomes suited to the local context, but concrete enough to provide enough guidance for those changes to be enacted successfully. Here, we apply these principles to two other change efforts-one that is proximal to the DAT project (the Teaching Quality Framework) and one that is more distal to the DAT project (the learning assistant model). Our purpose here is not to comprehensively explore the extent to which the principles were embedded in these two contexts, but rather to suggest that they are beneficial when present. An important area of future work would be to more systematically research the principles' impact in these and other contexts.

\section{The teaching quality framework (TQF) initiative}

The teaching quality framework initiative is a sibling project to the DAT project. The TQF initiative uses departmentally based teams to contextualize a common scholarly framework for assessing teaching quality and to support the framework's relevance and use within their own departments $[130,131]$. Structurally, TQF teams are similar to DATs; they represent a diverse subset of department members, are facilitated by an external facilitator, and meet regularly.

Several of our project's principles are present within the TQF project. Students are partners (principle 1) in two key fashions. First, student voice in the assessment of teaching is considered essential and TQF departmental teams review approaches about how to most effectively include student voice in the evaluation of teaching. Second, students are included in cross-departmental, campus-wide discussions of the project overall. The departmental groups engage in shared visioning activities (principle 2) to generate a collective understanding of teaching quality and how the various categories of educational practice might be measured specific disciplinary contexts. TQF explicitly collects data (principle 3) from multiple data sources (peer evaluations, student evaluations, and self-evaluations) and attends to how these multiple data sources all speak to different facets of teaching. This attention to multiple data sources and interpretations allows for a more comprehensive understanding of one's teaching [131]. TQF meetings also intentionally build community (principle 4) through norms such as eating together [130], which support the team in building a sense of community and in it togetherness. The frameworks that departments create are viewed as "living documents" that evolve over time and respond to campus-wide efforts to assess teaching quality [130] (principle 5). Finally, in several (though not all) contexts, specific attention is being paid to evaluations that reward and value attention to equity, inclusion, and social justice (principle 6); notably the application of these principles to the TQF initiative highlights areas where the initiative can be more intentional about its own commitments.

\section{The learning assistant (LA) model}

The learning assistant (LA) model was initially developed at the University of Colorado Boulder [132]. LAs are undergraduate students who support evidence-based and interactive classes; they have recently taken a given course and are trained in pedagogy. They assist instructors in university classes through facilitating active learning and discussion within and outside class meetings. Extensive research has been done on the benefits of LAs in reformed classrooms [66,132].

Several of our project's principles have been documented in LA programs. Research by Sabella et al. shows that LAs can work in collaborative partnerships with faculty [66] (principle 1). These collaborative partnerships leverage the 
unique expertise of the LAs to understand what it is like to be a student in that context. Additionally, the LA model itself involves a clear shared vision for improving STEM undergraduate education through cultivating future teachers, involving disciplinary faculty in teacher preparation, and shifting cultures to value research-based instructional strategies [132] (principle 2). Such a shared vision has directly informed assessment metrics and programmatic activity. LA programs also use multiple validated instruments to inform decision making [132] (principle 3). There is also evidence that community-building (principle 4) is a significant aspect of the LA experience and is consequential to LAs' trajectories in physics [133]. While not a central aspect of the LA model, some LA programs have explicitly attended to equity (principle 6) [134], and the presence of learning assistants has been shown to reduce inequities in classes [135].

\section{Principles are not enough}

We believe that fostering departmental change requires more than principles alone. The potential of the principles ultimately depends on the department in which the change effort is embedded and how they are enacted. Many factors contribute to a department's readiness for change, including having available resources, sufficient cultural alignment, and organizational capacity $[15,38]$. As an example, a department in which members lack a sense of collective departmental identity can be challenging to lead into developing a shared vision. This is because individual members need to feel somewhat part of a group to be able to envision a future for that group. Other departments may not be able to invest resources in DAT-like changes, because departments are complex systems with a multiplicity of priorities. Within our own project, we assess departments' readiness for change when we decide whether to invest DAT resources in them (cf. Ref. [136]).

We reiterate our claim that principles are but one component of a successful institutional transformation, and they must be intertwined with an effective change model that specifies the practices and approaches to change. We see our principles as providing theoretical knowledge about how effective change happens. While they do not prescribe any given practices or approaches to change, they do underlie many components of the DAT model. The DAT model consists of a variety of practicesregular meetings, student membership in groups, external facilitation - and these activities are imbued with meaning because facilitators are guided by our six principles. In this way, the DAT model contains one set of practices that can be used to effectively enact our principles, but it is not the only one. We see this connection between theory and practice as necessary; practices should enact theoretical commitments.

\section{Future work}

These principles are our aspirational goals for the development of the DAT model itself as we iterate on it over time. Self-education and reflection support our iterative, continuous improvement of our understanding of them; through developing and enacting the principles, we learn more about what they mean to us. These principles have undergone four major evolutions as a result of their implementation in our work. Looking forward, we expect the principles to continue becoming refined in response to the environment in which they are embedded. The practices of higher education will continue to evolve as internal and external pressures shift. This is especially true as institutional change work continues to positively impact higher education. As the educational landscape evolves, we expect these principles to evolve as well.

\section{ACKNOWLEDGMENTS}

We thank Dimitri Dounas-Frazer, Benjamin Pollard, Laura Ríos, Janet Tsai, and thoughtful anonymous reviewers for their feedback on this work. This work is supported by NSF DUE-1626565.
[1] M. Stains, J. Harshman, M. K. Barker, S. V. Chasteen, R. Cole, S. E. DeChenne-Peters, M. Eagan, J. M. Esson, J. K. Knight, F. A. Laski et al., Anatomy of STEM teaching in North American universities, Science 359, 1468 (2018).

[2] M. Borrego and C. Henderson, Increasing the use of evidence-based teaching in STEM higher education: A comparison of eight change strategies, J. Engin. Educ. 103, 220 (2014).

[3] C. Henderson, A. Beach, and N. Finkelstein, Facilitating change in undergraduate STEM instructional practices:
An analytic review of the literature, J. Res. Sci. Teach. 48, 952 (2011).

[4] C. Henderson and M. H. Dancy, Impact of physics education research on the teaching of introductory quantitative physics in the United States, Phys. Rev. ST Phys. Educ. Res. 5, 020107 (2009).

[5] S. Olson and D. G. Riordan, Engage to Excel: Producing One Million Additional College Graduates with Degrees in Science, Technology, Engineering, and Mathematics, Report to the President (Executive Office of the President, 2012). 
[6] AAAS, Vision and Change: A Call to Action, Technical Report, 2011.

[7] T. C. for Reform of Undergraduate STEM Education, Achieving Systemic Change: A Source-book for Advancing and Funding Undergraduate STEM Education (Association of American Colleges and Universities, Washington, DC, 2014).

[8] J. C. Corbo, D. L. Reinholz, M. H. Dancy, S. Deetz, and N. Finkelstein, Framework for transforming departmental culture to support educational innovation, Phys. Rev. Phys. Educ. Res. 12, 010113 (2016).

[9] K. Foote, A. Knaub, C. Henderson, M. Dancy, and R. J. Beichner, Enabling and challenging factors in institutional reform: The case of SCALE-UP, Phys. Rev. Phys. Educ. Res. 12, 010103 (2016).

[10] C. Henderson and M. H. Dancy, Barriers to the use of research-based instructional strategies: The influence of both individual and situational characteristics, Phys. Rev. ST Phys. Educ. Res. 3, 020102 (2007).

[11] K. Q. Fisher and C. Henderson, Department-level instructional change: Comparing prescribed versus emergent strategies, CBE Life Sci. Educ. 17, ar56 (2018).

[12] A. Kezar and S. Elrod, Facilitating interdisciplinary learning: lessons from project kaleidoscope, Change: The Magazine of Higher Learning 44, 16 (2012).

[13] C. Wieman, Improving How Universities Teach Science: Lessons from the Science Education Initiative (Harvard University Press, Cambridge, MA, 2017).

[14] R. Khatri, C. Henderson, R. Cole, J. E. Froyd, D. Friedrichsen, and C. Stanford, Designing for sustained adoption: A model of developing educational innovations for successful propagation, Phys. Rev. Phys. Educ. Res. 12, 010112 (2016).

[15] S. Elrod and A. Kezar, Increasing student success in STEM, Peer Review 17, 4 (2015).

[16] A. V. Knaub, C. Henderson, and K. Q. Fisher, Finding the leaders: an examination of social network analysis and leadership identification in STEM education change, Int. J. STEM Educ. 5, 26 (2018).

[17] K. Q. Fisher, C. Henderson, and C. G. Reiness, Department-level instructional change: Comparing prescribed versus emergent strategies, CBE Life Sci. Educ. 17, $\operatorname{ar} 56$ (2018).

[18] A. Olmstead, A. Beach, and C. Henderson, Int. J. STEM Educ. (to be published).

[19] V. Svihla and R. Reeve, Design as Scholarship: Case Studies from the Learning Sciences (Routledge, Abingdon, UK, 2016).

[20] B. Kirshner and J. L. Polman, Adaptation by design: A context-sensitive, dialogic approach to interventions, Yearbook of the National Society for the Study of Education 112, 215 (2013).

[21] M. C. Linn, Internet Environments for Science Education (Routledge, Abingdon, UK, 2013).

[22] Y. Kali, The design principles database as a means for promoting design-based research, in Handbook of Design Research Methods in Education: Innovations in Science, Technology, Engineering, and Mathematics Learning and Teaching (Routledge, New York, NY, 2008).
[23] R. A. Engle and F. R. Conant, Guiding principles for fostering productive disciplinary engagement: Explaining an emergent argument in a community of learners classroom, Cognit. Instr. 20, 399 (2002).

[24] A. S. Jurow, R. Hall, and J. Y. Ma, Expanding the disciplinary expertise of a middle school mathematics classroom: Re-contextualizing student models in conversations with visiting specialists, J. Learn. Sci. 17, 338 (2008).

[25] K. E. Metz, Children's understanding of scientific inquiry: Their conceptualization of uncertainty in investigations of their own design, Cognit. Instr. 22, 219 (2004).

[26] D. R. Dounas-Frazer, S. A. Hyater-Adams, and D. L. Reinholz, Learning to do diversity work: A model for continued education of program organizers, Phys. Teach. 55, 342 (2017).

[27] P. Cobb, J. Confrey, A. DiSessa, R. Lehrer, and L. Schauble, Design experiments in educational research, Educ. Res. 32, 9 (2003).

[28] M. Eisenhart, in Generalizing from Educational Research (Routledge, Abingdon, UK, 2009), pp. 61-76.

[29] M. T. Hora, J. Bouwma-Gearhart, and H. J. Park, Data driven decision-making in the era of accountability: Fostering faculty data cultures for learning, Rev. High. Educ. 40, 391 (2017).

[30] W. Sandoval, Conjecture mapping: An approach to systematic educational design research, J. Learn. Sci. 23, 18 (2014).

[31] M. Stains and T. Vickrey, Fidelity of implementation: An overlooked yet critical construct to establish effectiveness of evidence-based instructional practices, CBE Life Sci. Educ. 16, rm1 (2017).

[32] S. M. Hord et al., Taking Charge of Change (ERIC, 1987).

[33] D. L. Reinholz, J. C. Corbo, M. H. Dancy, and N. Finkelstein, Departmental Action Teams: Supporting faculty learning through departmental change, Learning Commun. J. 9 (2017).

[34] J. Corbo, D. Reinholz, M. Dancy, and N. Finkelstein, Proceedings of the 2015 Physics Education Research Conference, College Park, MD (AIP, New York, 2015), pp. $91-94$.

[35] E. H. Schein, Organizational Culture and Leadership (John Wiley \& Sons, New York, 2010), Vol. 2.

[36] P. M. Senge, The fifth discipline: The art and practice of the learning organization, Performance+Instruction 37 (1990).

[37] J. S. Brown and P. Duguid, Organizational learning and communities-of-practice: Toward a unified view of working, learning, and innovation, Organ. Sci. 2, 40 (1991).

[38] A. Kezar, How Colleges Change: Understanding, Leading, and Enacting Change (Routledge, Abingdon, UK, 2013).

[39] S. J. Quaye and S. R. Harper, Student Engagement in Higher Education: Theoretical Perspectives and Practical Approaches for Diverse Populations (Routledge, Abingdon, UK, 2014).

[40] R. J. Garmston and B. M. Wellman, The Adaptive School: A Sourcebook for Developing Collaborative Groups (Rowman \& Littlefield, Lanham, MD, 2008). 
[41] D. Cooperrider, D. D. Whitney, J. M. Stavros, and J. Stavros, The Appreciative Inquiry Handbook: For Leaders of Change (Berrett-Koehler Publishers, Oakland, CA, 2008).

[42] B. Wellman and L. Lipton, Data-Driven Dialogue: A Facilitator's Guide to Collaborative Inquiry (Mira Via, LLC, Arlington, MA, 2004).

[43] T. Brown, Design thinking, Harvard business review 86, 84 (2008).

[44] A. Lau, M. Dancy, J. Corbo, C. Henderson, and A. Rundquist, Proceedings of 2017 Physics Education Research Conference, Cincinnati, OH (AIP, New York, 2017), pp. 232-235.

[45] I. S. Horn, B. Garner, B. D. Kane, and J. Brasel, A taxonomy of instructional learning opportunities in teachers' workgroup conversations, J. Teach. Educ. 68, 41 (2017).

[46] I. S. Horn and B. D. Kane, Opportunities for professional learning in mathematics teacher workgroup conversations: Relationships to instructional expertise, J. Learn. Sci. 24, 373 (2015).

[47] J. Lave and E. Wenger, Situated learning: Legitimate peripheral participation (Cambridge University Press, Cambridge, England, 1991).

[48] E. Wenger, Communities of Practice: Learning, Meaning, and Identity (Cambridge University Press, Cambridge, England, 1999).

[49] J. S. Brown, A. Collins, and P. Duguid, Situated cognition and culture of learning, Educ. Res. 18, 32 (1989).

[50] S. M. Carter and C. R. Greer, Strategic leadership: Values, styles, and organizational performance, J. Leadership Org. Studies 20, 375 (2013).

[51] J. E. Dinh, R. G. Lord, W. L. Gardner, J. D. Meuser, R. C. Liden, and $\mathrm{J}$. Hu, Leadership theory and research in the new millennium: Current theoretical trends and changing perspectives, Leadership Quarterly 25, 36 (2014).

[52] M. Uhl-Bien, R. Marion, and B. McKelvey, Complexity Leadership Theory: Shifting leadership from the industrial age to the knowledge era, Leadership Quarterly 18, 298 (2007).

[53] A. S. Bryk, L. M. Gomez, and A. Grunow, Frontiers in Sociology of Education (Springer, New York, 2011), pp. 127-162.

[54] E. A. Schegloff, Sequence Organization in Interaction: Volume 1: A Primer in Conversation Analysis (Cambridge University Press, Cambridge, England, 2007), Vol. 1.

[55] B. Jordan and A. Henderson, Interaction analysis: Foundations and practice, J. Learn. Sci. 4, 39 (1995).

[56] S. J. Derry, R. D. Pea, B. Barron, R. A. Engle, F. Erickson, R. Goldman, R. Hall, T. Koschmann, J. L. Lemke, and M. G. Sherin, Conducting video research in the learning sciences: Guidance on selection, analysis, technology, and ethics, J. Learn. Sci. 19, 3 (2010).

[57] L. Mercer-Mapstone, S. L. Dvorakova, K. Matthews, S. Abbot, B. Cheng, P. Felten, K. Knorr, E. Marquis, R. Shammas, and K. Swaim, A systematic literature review of students as partners in higher education, Int. J. Students as Partners 1 (2017).
[58] C. Bovill, A framework to explore roles within studentstaff partnerships in higher education: Which students are partners, when, and in what ways?, Int. J. Students as Partners 1 (2017).

[59] K. Matthews, Students as partners as the future of student engagement, Student Engagement Higher Educ. J. 1 (2016).

[60] P. Felten, Emotion and partnerships, Int. J. Students as Partners 1 (2017).

[61] T. Hermsen, T. Kuiper, F. Roelofs, and J. van Wijchen, Without emotions, never a partnership!, Int. J. Students as Partners 1 (2017).

[62] J. P. Smith III, A. A. DiSessa, and J. Roschelle, Misconceptions reconceived: A constructivist analysis of knowledge in transition, J. Learn. Sci. 3, 115 (1994).

[63] D. Hammer and E. van Zee, Seeing the Science in Children's Thinking: Case Studies of Student Inquiry in Physical Science (Heinemann, Portsmouth, NH, 2006).

[64] A. D. Robertson, Valuing student ideas morally, instrumentally, and intellectually, Proceedings of the Physics Education Research Conference, College Park, MD, 2015 (2015), pp. 275-278, http://dx.doi.org/10.1119/ perc.2015.pr.064.

[65] K. Tobin, Learning to teach through coteaching and cogenerative dialogue, Teach. Teach. Educ. 17, 133 (2006).

[66] M. S. Sabella, A. G. Van Duzor, and F. Davenport, Leveraging the expertise of the urban STEM student in developing an effective LA Program: LA and Instructor Partnerships, Proceedings of the Physics Education Research Conference, Sacramento, CA, 2016 (2016), pp. 288-291, http://dx.doi.org/10.1119/perc.2016.pr.067.

[67] F. Davenport, F. Amezcua, M. S. Sabella, and A. G. Van Duzor, Exploring the Underlying Factors in Learning Assistant - Faculty Partnerships, Proceedings of the Physics Education Research Conference, Cincinnati, $\mathrm{OH}, 2017$ (2018), pp. 104-107, http://dx.doi.org/10 .1119/perc.2017.pr.021.

[68] M. L. Guha, A. Druin, and J. A. Fails, Cooperative Inquiry revisited: Reflections of the past and guidelines for the future of intergenerational co-design, Int. J. Child-Computer Interact. 1, 14 (2013).

[69] J. C. Yip, K. Sobel, C. Pitt, K. J. Lee, S. Chen, K. Nasu, and L. R. Pina, in Proceedings of the 2017 CHI Conference on Human Factors in Computing Systems, CHI '17 (ACM, New York, NY, USA, 2017), pp. 57425754.

[70] B. Kirshner, Guided participation in three youth activism organizations: Facilitation, apprenticeship, and joint work, J. Learn. Sci. 17, 60 (2008).

[71] J. Lindelow, Participative decision-making, School Leadership: Handbook for Excellence, edited by S. C. Smith and P. K. Piele (ERIC Publications, Eugene, OR, 1989).

[72] A. Somech and M. Wenderow, The impact of participative and directive leadership on teachers' performance: The intervening effects of job structuring, decision domain, and leader-member exchange, Educ. Admin. Quart. 46, 174 (2010).

[73] H. B. Carlone and A. Johnson, Understanding the science experiences of successful women of color: Science 
identity as an analytic lens, J. Res. Sci. Teach. 44, 1187 (2007).

[74] D. Holland, Identity and Agency in Cultural Worlds (Harvard University Press, Cambridge, MA, 2001).

[75] K. L. Lewis, J. G. Stout, S. J. Pollock, N. D. Finkelstein, and T. A. Ito, Fitting in or opting out: A review of key social-psychological factors influencing a sense of belonging for women in physics, Phys. Rev. Phys. Educ. Res. 12, 020110 (2016).

[76] K. D. Multon, S. D. Brown, and R. W. Lent, Relation of self-efficacy beliefs to academic outcomes: A metaanalytic investigation, J. Counsel. Psychol. 38, 30 (1991).

[77] M. J. Graham, J. Frederick, A. Byars-Winston, A.-B. Hunter, and J. Handelsman, Increasing persistence of college students in STEM, Science 341, 1455 (2013).

[78] Z. Hazari, G. Sonnert, P. M. Sadler, and M.-C. Shanahan, The impact of participative and directive leadership on teachers' performance: The intervening effects of job structuring, decision domain, and leader-member exchange, J. Res. Sci. Teach. 47, 978 (2010).

[79] K. Rainey, J. C. Corbo, D. L. Reinholz, and M. Betterton, Improving representation in physical sciences using a Departmental Action Team, Proceedings of the Physics Education Research Conference, Sacramento, CA, 2016 (2016), pp. 264-267, http://dx.doi.org/10.1119/perc.2016 .pr.061.

[80] G. Wiggins and J. Mctighe, Understanding by Design (Association for Supervision and Curriculum Development, Alexandria, VA, 1998).

[81] SERC, Ideal Student Exercise (2017), https://serc.carleton .edu/NAGTWorkshops/departments/degree_programs/ idealstudent.html.

[82] R. Halverson, J. Grigg, R. Prichett, and C. Thomas, The new instructional leadership: Creating data-driven instructional systems in school, J. School Leadership 17, 159 (2007).

[83] C. Erzberger and U. Kelle, Making inferences in mixed methods: The rules of integration, Handbook of Mixed Methods in Social and Behavioral Research, edited by A. Tashakkori and C. Teddlie, (SAGE, Thousand Oaks, CA, 2003), pp. 457-488.

[84] G. Biesta, Why "what works" won't work: Evidencebased practice, Educ. Theory 57, 1 (2007).

[85] C. E. Coburn and E. O. Turner, Research on data use: A framework and analysis, Meas. Interdiscip. Res. Perspect. 9, 173 (2011).

[86] R.S. Nickerson, Confirmation bias: A ubiquitous phenomenon in many guises, Rev. Gen. Psychol. 2, 175 (1998).

[87] A. Tversky and D. Kahneman, Availability: A heuristic for judging frequency and probability, Cogn. Psychol. 5, 207 (1973).

[88] H. Mehan, Learning Lessons (Harvard University Press, Cambridge, MA, 1979).

[89] J. P. Gee and J.L. Green, Discourse analysis, learning, and social practice: A methodological study, Rev. Res. Educ. 23, 119 (1998).

[90] K. Fujikawa, S. Perez-Darby, and M. Kaba, Building accountable communities (2018), http://bcrw.barnard .edu/building-accountable-communities/.
[91] K. Jones and T. Okun, Dismantling Racism: A Workbook for Social Change (2001), https://resourcegeneration.org/ wp-content/uploads/2018/01/2016-dRworks-workbook .pdf.

[92] I. Rodriguez, R. M. Goertzen, E. Brewe, and L. Kramer, Cookies as agents for community membership, AIP Conf. Proc. 1513, 342 (2013).

[93] A. Little, Proudness: What Is It? Why Is It Important? And How Do We Design for It in College Physics and Astronomy Education?, STATUS: A Report on Women in Astronomy, Newsletter (American Astronomical Society, 2015).

[94] T. Garavan, The learning organization: a review and evaluation, Learn. Organization 4, 18 (1997).

[95] K. Dorst and N. Cross, Creativity in the design process: Co-evolution of problem-solution, Design Studies 22, 425 (2001).

[96] M. B. Sanger and M. A. Levin, Using old stuff in new ways: Innovation as a case of evolutionary tinkering, J. Policy Analysis Manage. 11, 88 (1992).

[97] S. Turkle and S. Papert, Epistemological pluralism and the revaluation of the concrete, Signs J. Women Culture Soc. 16, 128 (1990).

[98] J. P. Kotter, Leading Change (Harvard Business School Press, Boston, 1996).

[99] I. Rodriguez, E. Brewe, V. Sawtelle, and L. H. Kramer, Impact of equity models and statistical measures on interpretations of educational reform, Phys. Rev. ST Phys. Educ. Res. 8, 020103 (2012).

[100] T. M. Philip and F. S. Azevedo, Everyday science learning and equity: Mapping the contested terrain, Sci. Educ. 101, 526 (2017).

[101] S. Hyater-Adams, C. Fracchiolla, N. Finkelstein, and K. Hinko, Critical look at physics identity: An operationalized framework for examining race and physics identity, Phys. Rev. Phys. Educ. Res. 14, 010132 (2018).

[102] K. Rosa and F. M. Mensah, Educational pathways of Black women physicists: Stories of experiencing and overcoming obstacles in life, Phys. Rev. Phys. Educ. Res. 12, 020113 (2016).

[103] I. Esmonde, Ideas and identities: Supporting equity in cooperative mathematics learning, Rev. Educ. Res. 79, 1008 (2009).

[104] A. R. Daane, S. R. Decker, and V. Sawtelle, Teaching about racial equity in introductory physics courses, Phys. Teach. 55, 328 (2017).

[105] R. E. Scherr and A. D. Robertson, Unveiling privilege to broaden participation, Phys. Teach. 55, 394 (2017).

[106] G. Ladson-Billings, From the achievement gap to the education debt: Understanding achievement in U.S. schools, Educ. Res. 35, 3 (2006).

[107] P. Freire, Pedagogy of the Oppressed (Bloomsbury Publishing, New York, NY, 1970).

[108] C. D. Lee, Historical evolution of risk and equity: Interdisciplinary issues and critiques, Rev. Res. Educ. 33, 63 (2009).

[109] R. S. Barthelemy, M. McCormick, and C. Henderson, Gender discrimination in physics and astronomy: Graduate student experiences of sexism and gender microaggressions, Phys. Rev. Phys. Educ. Res. 12, 020119 (2016). 
[110] A. J. Gonsalves, Exploring how gender figures the identity trajectories of two doctoral students in observational astrophysics, Phys. Rev. Phys. Educ. Res. 14, 010146 (2018).

[111] E. Seymour and N. M. Hewitt, Talking about Leaving: Why Undergraduates Leave the Sciences (Westview Press, Boulder, CO, 1997).

[112] S. Secules, A. Gupta, A. Elby, and C. Turpen, Zooming out from the struggling individual student: An account of the cultural construction of engineering ability in an undergraduate programming class, J. Engin. Educ. 107, 56 (2018).

[113] S. Traweek, Beamtimes and Lifetimes (Harvard University Press, Cambridge, MA, 2009).

[114] L. Pérez Huber and D. G. Solorzano, Racial microaggressions as a tool for critical race research, Race Ethnicity Educ. 18, 297 (2015).

[115] Ö. Sensoy and R. Diangelo, Developing social justice literacy an open letter to our faculty colleagues, Phi Delta Kappan 90, 345 (2009).

[116] T. C. Howard, Culturally relevant pedagogy: Ingredients for critical teacher reflection, Theory Into Practice 42, 195 (2003).

[117] G. Gay and K. Kirkland, Developing cultural critical consciousness and self-reflection in preservice teacher education, Theory Into Practice 42, 181 (2003).

[118] W. G. Stephan and K. Finlay, The role of empathy in improving intergroup relations, J. social issues 55, 729 (1999).

[119] A. G. Greenwald and L. H. Krieger, Implicit bias: Scientific foundations, Calif. L. Rev. 94, 945 (2006).

[120] D. L. Reinholz and N. Shah, Equity analytics: A methodological approach for quantifying participation patterns in mathematics classroom discourse, J. Res. Math. Educ. 49, 140 (2018).

[121] G. McAllister and J. J. Irvine, Cross cultural competency and multicultural teacher education, Rev. Educ. Res. 70, 3 (2000).

[122] R. D. Reason, Student engagement in higher education: Theoretical perspectives and practical approaches for diverse populations, Engaging White Students on Multicultural Campuses, edited by S. J. Quaye and S. R. Harper p. 75 (Routledge, 2014).

[123] Ö. Sensoy and R. DiAngelo, "We are all for diversity, but ...": How faculty hiring committees reproduce whiteness and practical suggestions for how they can change, Harv. Educ. Rev. 87, 557 (2017).

[124] F. J. Milliken, C. A. Bartel, and T. R. Kurtzberg, Diversity and creativity in work groups: A dynamic perspective on the affective and cognitive processes that link diversity and performance, Group Creativity: Innovation Through Collaboration, edited by P. B. Paulus and B. A. Nijstad (Oxford, New York, NY, US, 2003), pp. 32-62.

[125] R. Shehab, T. J. Murphy, and C. E. Foor, "Do they even have that anymore": the impact of redesigning a minority engineering program, J. Women Minorities Sci. Engin. 18 (2012)

[126] K. Crenshaw, Mapping the margins: Intersectionality, identity politics and Violence against women of color, Stanford L. Rev. 43 (1990).

[127] K. K. Kumashiro, Toward a theory of anti-oppressive education, Rev. Educ. Res. 70, 25 (2000).

[128] E. Bonilla-Silva, Racism without Racists: Color-Blind Racism and the Persistence of Racial Inequality in the United States (Rowman \& Littlefield Publishers, Lanham, MD, 2006).

[129] R. DiAngelo, White fragility, Int. J. Critical Pedagogy 3 (2011).

[130] J. Keating et al., Towards a Framework for Supporting and Assessing Teaching Quality at CU-Boulder (2016), https://www.colorado.edu/teaching-quality-framework/ sites/default/files/attached-files/tqf_whitepaper_2016-117.pdf.

[131] N. Finkelstein, J. C. Corbo, D. L. Reinholz, M. Gammon, and J. Keating, Evaluating teaching in a scholarly manner: A model and call for an evidence-based, departmentallydefined approach to enhance teaching evaluation for $\mathrm{CU}$ Boulder (2017), https://www.colorado.edu/teachingquality-framework/sites/default/files/attached-files/201711_tqf-white-paper_norecs.pdf.

[132] V. Otero, S. Pollock, and N. Finkelstein, A physics department's role in preparing physics teachers: The Colorado learning assistant model, Am. J. Phys. 78, 1218 (2010).

[133] E. W. Close, J. Conn, and H. G. Close, Becoming physics people: Development of integrated physics identity through the Learning Assistant experience, Phys. Rev. Phys. Educ. Res. 12, 010109 (2016).

[134] G. M. Quan, A. Gupta, C. Turpen, and E. Tanu, Designing a Course for Peer Educators in Undergraduate Engineering Design Courses, Proceedings of the 2017 ASEE Annual Conference and Exposition (2017).

[135] B. V. Dusen, J.-S. S. White, and E. A. Roualdes, Proceedings of the 2016 Physics Education Research Conference, Sacramento, CA (AIP, New York, 2016), pp. 360-363.

[136] D. L. Reinholz, M. E. Pilgrim, K. Falkenberg, C. Ngai, G. Quan, S. Wise, C. Geanious, J. Corbo, and N. Finkelstein, Departmental Action Teams: A five-year update on a model for sustainable change, Proceedings of the Reinvention Collaborative, Arlington, VA, 2018. 